\title{
A LIMIT CONJECTURE ON THE NUMBER OF HAMILTONIAN CYCLES ON THIN TRIANGULAR GRID CYLINDER GRAPHS ${ }^{1}$
}

\author{
Olga BodrožA-PANtić \\ Faculty of Sciences, Department of Mathematics and Informatics \\ University of Novi Sad, Novi Sad, Serbia \\ e-mail: olga.bodroza-pantic@dmi.uns.ac.rs \\ HARRIS KWONG \\ SUNY at Fredonia, Department of Mathematical Sciences \\ Fredonia, NY 14063, USA \\ e-mail: kwong@fredonia.edu \\ RADE DOROSLOVAČKI \\ Faculty of Technical Sciences \\ University of Novi Sad, Novi Sad, Serbia \\ e-mail: ftndean@uns.ac.rs \\ AND \\ Milan Pantić \\ Faculty of Sciences, Department of Physics \\ University of Novi Sad, Novi Sad, Serbia \\ e-mail: mpantic@df.uns.ac.rs
}

\begin{abstract}
We continue our research in the enumeration of Hamiltonian cycles (HCs) on thin cylinder grid graphs $C_{m} \times P_{n+1}$ by studying a triangular variant of the problem. There are two types of HCs, distinguished by whether they wrap around the cylinder. Using two characterizations of these HCs, we prove that, for fixed $m$, the number of HCs of both types satisfy some linear recurrence relations. For small $m$, computational results reveal that the two
\end{abstract}

\footnotetext{
${ }^{1}$ This work was supported by the Ministry of Education and Science of the Republic of Serbia (Grants OI 174018, OI 174026, OI 171009 and III 46005).
} 
numbers are asymptotically the same. We conjecture that this is true for all $m \geq 2$.

Keywords: contractible Hamiltonian cycles, generating functions, thin triangular grid cylinder graph.

2010 Mathematics Subject Classification: Primary 05C30; Secondary 05C50, 05A 15 .

\section{REFERENCES}

[1] O. Bodroža-Pantić, B. Pantić, I. Pantić and M. Bodroža-Solarov, Enumeration of Hamiltonian cycles in some grid graphs, MATCH Commun. Math. Comput. Chem. 70 (2013) 181-204.

[2] O. Bodroža-Pantić, H. Kwong and M. Pantić, Some new characterizations of Hamiltonian cycles in triangular grid graphs, Discrete Appl. Math. 201 (2016) 1-13. doi:10.1016/j.dam.2015.07.028

[3] O. Bodroža-Pantić, H. Kwong and M. Pantić, A conjecture on the number of Hamiltonian cycles on thin grid cylinder graphs, Discrete Math. Theoret. Comput. Sci. 17 (2015) 219-240.

[4] O. Bodroža-Pantić and R. Tošić, On the number of 2-factors in rectangular lattice graphs, Publ. Inst. Math. (Beograd) (N.S.) 56 (1994) 23-33.

[5] D.M. Cvetković, M. Doob and H. Sachs, Spectra of Graphs: Theory and Application (VEB Deutscher Verlag der Wissenschaften, Berlin, 1982).

[6] F.J. Faase, On the number of specific spanning subgraphs of the graphs $G \times P_{n}$, Ars Combin. 49 (1998) 129-154.

[7] M.J. Golin, Y.C. Leung, Y. Wang and X. Yong, Counting structures in grid-graphs, cylinders and tori using transfer matrices: survey and new results (extended abstract), in: Proceedings of SIAM ALENEX/ANALCO Workshop-Analytic Algorithmics and Combinatorics (Canada, 2005), 250-258.

[8] J.L. Jacobsen, Exact enumeration of Hamiltonian circuits, walks and chains in two and three dimensions, J. Phys. A 40 (2007) 14667-14678. doi:10.1088/1751-8113/40/49/003

[9] I. Jensen, Self-avoiding walks and polygons on the triangular lattice, J. Stat. Mech. Theory Exp. (2004) P10008. doi:10.1088/1742-5468/2004/10/P10008

[10] A.M. Karavaev, Kodirovanie sostoyanüi v metode matricy perenosa dlya podscheta gamil'tonovyh ciklov na pryamougol'nyh reshetkah, cilindrah i torah, Informacionnye Processy 11 (2011) 476-499 (in Russian).

[11] A. Karavaev and S. Perepechko, Counting Hamiltonian cycles on triangular grid graphs, IV International Conference (Kiev, 2012).

[12] B.P. Kitchens, Symbolic Dynamics: One-sided, Two-sided and Countable State Markov Shifts (Springer, 1997). 
[13] G. Kreweras, Dénombrement des Cycles Hamiltoniens dans un Rectangle Quadrillé, European J. Combin. 13 (1992) 473-467.

doi:10.1016/0195-6698(92)90005-K

[14] Y.H.H. Kwong, Enumeration of Hamiltonian cycles in $P_{4} \times P_{n}$ and $P_{5} \times P_{n}$, Ars Combin. 33 (1992) 87-96.

[15] Y.H.H. Kwong and D.G. Rogers, A matrix method for counting Hamiltonian cycles on grid graphs, European J. Combin. 15 (1994) 277-283. doi:10.1006/eujc.1994.1031

[16] M. Peto, T.Z. Sen, R.L. Jernigan and A. Kloczkowski, Generation and enumeration of compact conformations on the two-dimensional triangular and three-dimensional fcc lattices, J. Chem. Phys. 127 (2007) Article 044101.

[17] T.G. Schmalz, G.E. Hite and D.J. Klein, Compact self-avoiding circuits on two dimensional lattice, J. Phys. A 17 (1984) 445-453. doi:10.1088/0305-4470/17/2/029

[18] R.P. Stanley, Enumerative Combinatorics, Vol. I (Cambridge University Press, Cambridge, 2002).

[19] R. Stoyan and V. Strehl, Enumeration of Hamiltonian circuits in rectangular grids, J. Combin. Math. Combin. Comput. 21 (1996) 109-127.

[20] R. Tošić, O. Bodroža, Y.H.H. Kwong and H.J. Straight, On the number of Hamiltonian cycles of $P_{4} \times P_{n}$, Indian J. Pure Appl. Math. 21 (1990) 403-409.

Received 1 April 2016

Revised 20 October 2016

Accepted 5 December 2016 